\title{
FIESTAS PROFANAS Y DIVERSIONES DE LA COMUNIDAD MORISCA ARAGONESA
}

Los moriscos gustaban de divertirse. Aznar Cardona evoca, no sin cierto desprecio y hostilidad, esa inclinación de la población musulmana de España por las fiestas y los juegos:

Eran muy amigos de burlerías, cuentos, berlandinas y sobre todo amicísimos (y así tenían comúnmente gaytas, sonajas y adufes) de bayles, danzas solazes, cantarzillos, albadas, paseos de huertas y fuentes y de todos los entretenimientos bestiales en que con descompuesto bullicio y gritería suelen ir los mozos villanos vozinglando por las calles. Vanagloriábanse de baylones, jugadores de pelota y de la estornija, tiradores de bola y del canto y corredores de toros y otros hechos semejantes de gañanes'.

Entre 1549 y 1609, las fuentes inquisitoriales a menudo hacen hincapié en fiestas organizadas con motivo de reveses - verda. deros o falsos - de los españoles. Así, la eventual llegada del turco a suelo ibérico, las victorias de los moros sobre España o el desastre del ejército español en Portugal sirven de pretexto para realizar festividades moriscas que duran muchos días.

Desde 1549, el proceso de Jerónimo Montagudo, morisco de Híjar, hace alusión a una fiesta organizada para celebrar una posible intervención turca en España. Una noche, cuentan los testigos, todos los conversos recientes de Hijar salieron a las calles vestidos a la morisca, con las caras cubiertas por máscaras y lunas azules pintadas en los brazos. Al ser interrogados por el Santo Oficio, algunos declararon que habían organizado esos festejos para celebrar la próxima llegada de los turcos, otros afirmaron que se trataba de una antigua costumbre mora que se practicaba con ocasión de un repudio ${ }^{2}$. Tiempo más tarde, en 1558 y 1560, los

${ }^{1}$ Pedro Aznar Cardona, Expulsión justificada de los moriscos españoles y suma de las excellencias de nuestro rey don Felipe el Católico tercero deste nombre, Huesca, 1612, pp. $34 \mathrm{~s}$.

${ }^{2}$ Archivo Histórico Nacional (A.H.N.), Inquisición de Zaragoza (Inq.), libro 988, fol. 110: "Jerónimo Montagudo morisco, teniente que era de los con- 
moriscos aragoneses preparan fiestas públicas, con lanzamiento de jabalinas y corridas de toros, después de recibir la noticia del desembarco de una armada turca en Barcelona. Un testimonio más: el del cura de Torrellas, que el 28 de noviembre de 1569 afirma haber escuchado desde hace dos o tres noches a una decena de moriscos que cantaban en el puente de la aldea la siguiente copla:

$$
\begin{aligned}
& \text { Christianenos de Granada } \\
& \text { Que subís al Alpujarra, } \\
& \text { Subís en hora buena } \\
& \text { Y bajarêis en hora mala, }
\end{aligned}
$$

Al ser detenidos por la Inquisición, los recién conversos declararon que manifestaban su alegría por el hecho de saber que los turcos llegarían muy pronto ${ }^{4}$.

El desastre del ejército español en Portugal presenta también para los moriscos de Aragón motivo para manifestar su satisfacción, cosa que los cristianos consideraban una provocación: "Es grandísima lástima ver su pertinacia y desvergüenza", escribe en 1578 un inquisidor de Zaragoza ${ }^{5}$.

Sucede lo mismo en ocasión de la pérdida de la Goleta, plaza fuerte española en Túnez. Alexandro Tarazona, morisco de Zaragoza, celebra en compañía de sus correligionarios esta victoria musulmana; un testigo afirma haberlo visto tocar la cornamusa en las calles de la ciudad: "Cuando se perdió La Goleta y hacían regocijo los moriscos, andaba este reo por la ciudad tañendo una gayta"6.

vertidos de villa de Híjar, fue preso porque hubo información que estando las galeras del Turco en la costa de Barcelona el año pasado, los convertidos de Hijar hizieron muy grande regocijo saliendo de noche disfrazados a la morisca con lunas azules pintadas en los brazos, cubiertos los rostros y hubo convertidos que decían lo hacían por el contentamiento que tenían de la venida del Turco y hubo dello grande escándalo entre los cristianos viejos..."; véase LOUIS CARDAILlAC, "Morisques et turcs au XVI $\mathrm{e}^{\mathrm{e}}$ siècle en Espagne", Actes du I Congrès International d'Histoire du Maghreb, Túnez, 1974.

${ }^{3}$ Archivo de la Corona de Aragón, Concejo de Aragón, leg. 221; A.H.N., Inq., libro 1213, fol. 215: “. . . Así en el dicho reyno como en las costas de $\mathrm{Ca}$ taluña y Valencia de lo cual se tuvieron manifiestos indicios y demostraciones el año de 1558, quando la armada del Turco quiso venir sobre Barcelona que antes que viniese ya lo sabían los convertidos y quando la dicha armada llegó fue tanto el regocijo que mostraron y tan desvergonzadamente que muchos lugares hicieron fiestas y regocijos públicos por ello en unos jugando cañas vestidos a la morisca, en otros corriendo toros..."

${ }^{4}$ A. H. N., Inq., libro 962 , fol. 332 .

${ }^{5}$ A. H. N., Inq., libro 964 , fol. 144.

${ }^{6}$ A. H. N., Inq., libro 989, fol. 57. 
Por la correspondencia de los inquisidores a la Suprema, sabemos que los moriscos aragoneses de Riela, Gelsa, Séstrica, Brea, Sabiñán, etc., prepararon toda una serie de festividades durante el verano de 1609. Pensando que España estaría en un futuro muy próximo en manos de los turcos, los recién conversos aragoneses manifestaron su regocijo. Frente a esta alegría, la población cristiana que se siente amenazada se inquieta y a la vez se irrita, como cierta cristiana vieja de Brea: "Se espantaba de las alegrías que mostraban tener los moriscos y fiestas que hacían"?

Los testigos cristianos proporcionaban algunos detalles sobre esas fiestas amenizadas por corridas de toros, bailes y conciertos. En Gelsa, el párroco Mosén Miguel López cuenta que durante dos meses los conversos nuevos estuvieron particularmente alegres; se formaron grupos de hombres y mujeres en los huertos y en el monte, y todo el mundo cantaba y bailaba al compás de los tamboriles. En Almonacid de la Sierra, un cristiano declara que los moriscos estaban muy contentos y que bailaban alrededor de las fogatas. Sucede lo mismo en Riela, que cada noche es teatro de grandes fiestas con corridas de toros, bailes y conciertos de guitarra: "Lo que nunca se ha visto", especifica un testigo cristiano. El 12 de agosto de 1609, el notario cristiano de Séstrica comunica a la Inquisición que vio a jóvenes moriscos deambular por las calles tocando la trompeta y a mujeres que cantaban y danzaban. El guardia de Brea confirma también que nunca ha visto entre los moriscos tanto regocijo fuera de sus fiestas religiosas regulares (ibid., loc. cit.).

En ocasiones el pretexto para la diversión será proporcionado cuando los propios delatores cristianos nuevos son arrestados por el Santo Oficio. El encarcelamiento de los soplones Gerónimo Galif, en Fuentes, y de Agustín Colato, en Ambel, trae consigo ocho días de fiestas en la comunidad morisca: "estuvieron ocho días holgándose y haciendo fiestas por la prisión de Gerónimo Galif, morisco de Fuentes, y Agustín Colato, morisco de Ambel, que están presos en este Santo Oficio"8.

La forma en que los moriscos emplean sus ratos de ocio aparece de tiempo en tiempo en los archivos inquisitoriales. Las reuniones amistosas son frecuentes entre miembros de una misma comunidad. Se trata generalmente de reuniones informales

${ }^{7}$ A. H. N., Inq., legajo 1808, núm. 10.

${ }^{8}$ Ibid. Sucedía lo mismo cuando se trataba del crimen de algún familiar. A. H. N., Inq., libro 1213, fol. 215v. 
donde se disfruta de la discusión; a veces se invita a músicos o a cantores para amenizar la velada ${ }^{9}$.

También se manifiesta el gusto por el teatro: si algunos recién conversos se dedican a organizar ellos mismos representaciones destinadas exclusivamente a un público morisco ${ }^{10}$, otros, como el conocido morisco Juan de Albariel, prefieren asistir a las comedias; dichas piezas son representadas en la aldea ("en el teatro donde públicamente se hacen las comedias"11) y reúnen un público mezcla de cristianos y musulmanes. Como es natural, los espectadores se observan mutuamente. Al día siguiente siete cristianos viejos informarán al Santo Oficio que Juan de Albariel no llevaba esa noche el hábito de penitente que le había impuesto la Inquisición. Varios testigos que lo han observado cuidadosamente afirman que se había quitado el hábito en un rincón antes de entrar a la sala y que después se lo volvió a poner antes de salir ${ }^{12}$.

Los juegos ocupaban un lugar relativamente importante. Funcionaban aparentemente como diversión, pero también como ocasiones para oponerse concretamente a la sociedad cristiana, sobre todo durante la Semana Santa. De ahí que ciertos recién conversos instalaran mesas de juego en sus hogares. Es el caso de Gerónimo Corral, guardia morisco de Brea encargado oficialmente por el Santo Oficio de la tarea de obligar a sus correligionarios a asistir a misa. Empero, no duda en invitar a los miembros de su comunidad a jugar en su casa durante la celebración de los oficios religiosos: "Tenía en su casa tablaje de juego y consentía que jugasen las fiestas jueves y viernes sancto celebrándose los oficios divinos y hacía otras cosas indevidas"'13.

Estas diversiones que ocasionalmente ponian en contacto a cristianos y moriscos subrayan la ambigüedad de sus relaciones humanas: "La ambigüedad preside toda relación social entre ambas comunidades"14. El juego de cartas, al permitirles conocerse mejor, revela a los primeros, después de cierto tiempo, las creencias musulmanas de los otros. De ahí que dichos juegos fuesen el origen de gran número de procesos. Es el caso del posadero moris-

${ }^{9}$ Francisco Macho y ORTEGA, Condición social de los mudéjares aragoneses, Zaragoza, 1913, p. 480.

${ }^{10}$ A. H. N., Inq., lib. 990 , fol. 368.

${ }^{11}$ A. H. N., Inq., lib. 968, fol. 55.

${ }^{12}$ A. H. N., Inq., lib. 990, fol. 92, núm. 128.

${ }^{13}$ A. H. N., Inq., lib. 989, fol. 811. Gerónimo Corral es condenado en 1491 a ocho años de galeras y a doscientos latigazos.

${ }^{14}$ Luis CaRdalllaC, Moriscos y cristianos: un enfrentamiento polémico, México, 1979, p. 22; primera ed. francesa, 1977. 
co de Malón, Amador Palomo. Al ver que estaba a punto de perder una partida de naipes, empezó a blasfemar: "Descreo de Dios y de todas sus obras". Inmediatamente sus tres compañeros de juego, que eran cristianos, hicieron llegar la historia al Santo Oficio $^{15}$. De la misma manera, Juan de Aragón, herrero morisco de Fuentes de Ebro, "jugando a los naipes", aconsejaba a un cristiano viejo con mala fortuna que se pusiera bajo la protección de Alá "y le iría bien"16.

Por último, durante la partida de naipes entre un cristiano viejo y el morisco Gerónimo Alborje, éste, seguro de ganar, exclama que Mahoma acaba de hacer un milagro. Irritado por lo que oye y, quizá, por la idea de perder, el jugador cristiano previene a su adversario en el juego que Mahoma no lo ayudará en los días siguientes, dando a entender que lo denunciará ante la Inquisición ${ }^{17}$.

Sin embargo, las relaciones entre los moriscos y los cristianos no son siempre tan tensas: cristianos viejos de Caspe van a la morería (el barrio de San Juan) para entretenerse con juegos de azar: "En el dicho barrio de Sanct Joan de algunos días a esta parte, los vezinos del con otros cristianos viejos vezinos de la dicha villa se hayan dado a la ociosidad, vicios y juegos de naipes y dados" 18 .

Las actividades deportivas como el juego de pelota reunían igualmente a jóvenes cristianos y moriscos. A veces sucede que se entablan amistades entre miembros de las dos comunidades. Así ocurre que Juan Cortés, hijo del familiar de Caspe, considere que el morisco Pedro de Luna es su mejor amigo "por ser jugador de pelota" como él. Juan llega a aceptar prestarle un puñal para asustar a una mujer que lo había ofendido. Durante el proceso que se le sigue a Pedro, Juan interviene a su favor, pero los servicios prestados al morisco conducen a Juan Cortés a la Inquisición, que le condena a seis meses de exilio de Caspe y una multa de veinte escudos ${ }^{19}$.

${ }^{15}$ A. H. N., Inq., lib. 990, fol. 205. Fue condenado a abjurar de levi durante un auto de fe.

${ }^{16}$ A. H. N., Inq., lib. 989, fol. 403.

${ }^{17}$ A. H. N., Inq., lib. 990, fol. 345.

${ }^{18}$ A. H. N., Órdenes militares San Juan, Jerusalén, Castellanía de Amposta, legajo 245 (I) núm. 9, fol. 4v, citado por GREGORIo Colás LATORRE, La Bailía de Caspe en los siglos xvi y xvii, Zaragoza, 1978. Dicho autor señala que a los moriscos de Caspe les estaba prohibido "tener mesas de juegos, naipes, da. dos a ninguna persona de este barrio ni otra extrangeras rifando turrones ni otra cualquier cosa" (misma fuente, legajo 245 (I) núm. 5, fol. Iv).

${ }^{19}$ A. H. N., Ing., lib. 990, fol. 345. 
La práctica del juego de jabalina (juego de cañas) está atestiguada en una carta de la Inquisición de Zaragoza, dirigida el 30 de mayo de 1560 a la Suprema. En esta misiva los inquisidores aragoneses informan que la posibilidad de un próximo arribo de la armada turca a Barcelona ha dado lugar dentro de la comunidad morisca a justas caballerescas en que los recién conversos "se vistieron como moros y hicieron juegos de cañas"

Las corridas de toros también acompañan las manifestaciones de regocijo provocadas por la eventual intervención de los turcos en España. Tomemos, por ejemplo, el caso de Brea en agosto de 1609. Ciertos notables moriscos de esa población aragonesa se proponen salir en busca de un toro y pagarlo a sus expensas. Al toro, al que se le amarró una cuerda para excitarlo más, se le deja suelto en el pueblo y en la campiña los jóvenes corren delante de la bestia. La corrida termina con la muerte del toro ${ }^{21}$. Esta diversión, muy apreciada por los moriscos, tiene un acusado carácter popular.

La fiesta carnavalesca, que aparece repetidas veces en las relaciones de causas o en la correspondencia inquisitorial, revela el universo mental de los cristianos nuevos. La fiesta funciona principalmente como un derivado social donde se expresa su rebelión contra el orden establecido. Los moriscos, entonces, representando su rebeldía, viven auténticamente su historia bajo la forma de un psicodrama ${ }^{22}$. Esta fiesta se realiza generalmente en el interior de un hogar morisco. Los maniquíes carnavalescos, construidos con materiales improvisados, encarnan a Cristo, a fin de oponerse mejor al fervor religioso de quienes los dominan.

20 A. H. N., Inq. lib. 988, fol. 80 . El juego se inicia con la presentación de los combatientes. Formados en cuadrilla y vestidos a la morisca, los caballeros van provistos de un escudo que sostienen en el brazo izquierdo. Al son de las trompetas entran a la liza y después se libra un simulacro de combate con espadas. Ante una señal uno de los grupos lanza sus cabalgaduras a toda velocidad y arroja sus jabalinas sobre el adversario. El juego continúa sin interrupción hasta que todos los caballeros hayan tomado parte en la lucha (véase MARCELIN DEFOURNEAUX, La vie quotidienne en Espagne au Siècle d'Or, Paris, 1964, p. 152). Los viajeros extranjeros, como Cock, a veces describen los juegos de cañas cuando sus actores son grandes señores. Con motivo de su viaje a Aragón en 1586, Cock evoca una justa caballeresca que se realizó entre la Aljafería y ìa ribera del Ebro. Cuarenta y ocho señores de Zaragoza, divididos en cuatro cuadrillas y vestidos a la morisca participaron en este torneo que duró todo el día 12 de marzo de 1586 (ENRIQUE COCK, Relación del viaje hecho por Felipe II en 1585 a Zaragoza, 'Barcelona y Valencia, Madrid, 1876).

${ }^{21}$ A. H. N., Inq., legajo 1808, núm. 10.

${ }^{22}$ Véase EDMOND CROS, L'aristocrate et le carnaval des gueux; étude sur le "Buscón" de Quevedo, Montpellier, 1975, p. 9. 
Investidos de una superioridad efímera, su gozo se manifiesta en la idea de vencer lo prohibido y de invertir el orden de las cosas. El ejemplo de la puesta en escena de Burbagueña se centra en la superposición de la veneración a Mahoma en oposición al destronamiento y a la humillación de Jesús. Esta desmitificación de la religión cristiana a favor del Islam se integra así al contexto de una reunión familiar. Escuchemos la declaración del sirviente de Miguel de Agreda. La historia tiene lugar la noche de Navidad. Toda la familia del herrero Miguel de Agreda se encuentra reunida, con algunas amistades, frente a las llamas de la chimenea. Con un gorro de colores sobre la cabeza, un morisco se sube a un banco y sostiene un crucifijo en una mano, mientras con la otra sostiene un objeto blanco; luego, señalando el objeto blanco, exclama que se trata de Mahoma, en quien hay que creer; a continuación muestra la mano que sostiene el crucifijo y declara que Jesús es un samaritano, un vagabundo, un mentiroso. Entonces todos los asistentes abofetean y azotan el crucifijo y después escupen uno tras otro el rostro de Cristo ${ }^{23}$.

La sátira religiosa se dirige igualmente en contra de los monjes, para ayudar a liberarse de la presión que ejerce la iglesia católica. En marzo de 1589, un testigo cristiano relata que al entrar a la casa de un morisco de Brea encontró una gran reunión de nuevos conversos. El morisco Miguel Navarro, disfrazado de monje, se deja tonsurar por un correligionario, lo cual provoca risas y bromas a costa de los eclesiásticos. El juego se termina ante la entrada inoportuna del cristiano viejo: inmediatamente el círculo se cierra en torno al monje para encubrirlo mejor: "Quedó tan escandalizado el cristiano viejo que le testificó" ${ }^{24}$

$¿$ Es el gusto por la mascarada lo que lleva a ciertos moriscos a burlarse de la fe cristiana y a entregarse a una mistificación burlesca? Veamos un asunto que trata la Inquisición de Zaragoza en su correspondencia a la Suprema: todo ocurre en Lérida en mayo de 1579, donde, después de un largo período de sequía, las autoridades religiosas organizan múltiples procesiones para obtener agua y buenas cosechas. Durante este período de fervor religioso, la población se entera con emoción de que cae lluvia en forma de espigas de trigo en la casa de un recién converso, Miguel Ángel. De inmediato todo el mundo acude al lugar a fin de presenciar el milagro con sus propios ojos. Sospechando algo, la In-

${ }^{23}$ A. H. N., Inq., libro 989, fol. 765.

${ }^{24}$ A. H. N., Inq., libro 989, fol. 816. 
quisición arresta a toda la gente de la casa, miembros de la familia y sirvientes. El sacristán que asistió al milagro narra los hechos. Por ser vecino es recibido de vez en cuando en casa de los moriscos. Una noche que pasaba delante de la casa de Miguel Ángel y su esposa éstos lo hacen entrar. Lo conducen a una pieza. A las diez de la noche, cuando el invitado decide irse a su casa, repentinamente siente que cae sobre él una lluvia de trigo. El testigo, profundamente confundido, con bastante inocencia se arrodilla y murmura con las manos juntas: In manus tuas, Domine, commendo spiritum meum. Los moriscos manifiestan un gran alborozo y le dicen que el mismo milagro ocurrió la víspera y que lo han invitado a entrar para que esparza la nueva. Al día siguiente el sacristán se apresura a difundir lo que ha pasado y toda la población se conmociona por el milagro.

La Inquisición interroga durante cierto tiempo a los autores de la farsa; éstos declaran que cuando se levantaron por la mañana todas las piezas de su casa estaban tapizadas de espigas de trigo. Naturalmente ignoraban su proveniencia. Después de un interrogatorio más a fondo, los inquisidores descubrieron la superchería de Miguel y de su esposa, quienes habían conseguido una caja de trigo unos días atrás. Su intención era burlarse de los fieles que asistían a las procesiones, también hacer comprender a todos que el Islam era una buena religión, puesto que se podía realizar un milagro en un hogar morisco ${ }^{25}$.

Al término de este estudio, podemos señalar que fiestas y diversiones en el seno de la comunidad morisca eran vividas con intensidad. Cada instante de felicidad se sentía como si fuese el último. Pero la alegría y la despreocupación a menudo se pagaban muy duramente, ya que la mayoría de las manifestaciones de regocijo que comenzaban jubilosamente terminaban en un juicio inquisitorial.

JACQUELINE FOURNEL GUÉRIN

Casa de Velázquez, Madrid.

${ }^{25}$ A. H. N., Inq., libro 964, fol. 226.

Traducción del artículo: Carmen Chuaqui. 